\title{
¿Diputados a la medida?
}

Los diputados salvadoreños, salvo contadas excepciones, gozan de una reputación poco envidiable. A sus pocas luces intelectuales y a sus no tan solventes méritos profesionales, se suman las prácticas y los vicios más aberrantes: tráfico de influencias, compra y venta de favores políticos, compadrazgos y nepotismo. En otras palabras, en los diputados salvadoreños se suelen aunar dos cosas extremadamente perniciosas para la convivencia social: la incapacidad y la corrupción. Ambas se alimentan mutuamente, con lo cual el daño social que producen es mayor. Diputados que por su incapacidad cometen los peores desatinos, pero también diputados que, además de incapaces, se aprovechan del cargo que ostentan para obtener prebendas y beneficios a cambio de favores políticos: ésta es la cruda realidad política de El Salvador, luego de ocho años de firmados los acuerdos de paz. Рara no ir más lejos, el actual presidente de la Asamblea Legislativa, Ciro Cruz Zepeda, dejó en 1989 el cargo de presidente de la Corte de Cuentas de la República con un lastre de sospechas de comupción que, hasta el momento, en lo absoluto se han aclarado. A la luz de esa realidad, los bajos niveles de participación ciudadana y la desconfianza abierta que manifiestan los salvadoreños hacia la política y los políticos encuentran su mejor razón de ser.

¿Acaso se puede confiar en unos políticos -es el caso de los diputados- que además de incapaces son corruptos? ¿Acaso son motivadoras para la participación ciudadana las decisiones tomadas a la ligera e irresponsablemente por un grupo de individuos cuyas credenciales son la incompeten- cia y la mediocridad? Como señala Mario Vargas Llosa, "nada desmoraliza y desmoviliza tanto el espíritu cívico como la sospecha de que quienes han obtenido la confianza popular pueden delinquir impunemente. Esta sospecha contamina a toda la clase política y genera apatía y cinismo, otros tantos antídotos contra la participación en la vida pública, sin la cual no hay democracia que lo sea de veras. El abstencionismo, que en algunas naciones llega a la mitad del electorado, es síntoma de lo gravísimo de esta enfermedad"'. Ni más ni menos, eso es lo que sucede en El Salvador de la postguerra. La desmoralización, la apatía y el cinismo son tan generalizados en la sociedad que no se ve cómo pueden ser revertidos en orden a propiciar unos niveles aceptables de participación ciudadana. No cabe duda que ello pasa por una renovación drástica de la clase política - de sus hábitos, costumbres y estilos de comportamiento-, lo cual no se ve que tenga visos de realidad en el futuro inmediato.

Los hábitos, costumbres y estilos de comportamiento de los diputados salvadoreños son el mejor ejemplo de lo que se puede esperar del conjunto de la clase política nacional. En efecto, a la larga lista de taras que ya parecen serles connaturales, los diputados suman en su haber, fuera del recinto legislativo, comportamientos y actitudes propias de delincuentes comunes. El ejemplo más reciente de esto lo constituye el diputado Francisco Merino quien, la madrugada del sábado 9 de septiembre, protagonizó un penoso incidente, en el cual resultó herida de bala una agente de la Policía Nacional Civil (PNC). Brevemente, las cosas sucedieron más

1. Mario Vargas Llosa, "Los nucvos rctos". En Desafios a la libertad, Madrid, Aguilar, 1994, pp. 206-207. 
o menos así: Merino, en estado de inocultable ebriedad, amenazó con su arma a un vigilante privado de una zona residencial; el incidente fue informado por una vecina al sistema de emergencias 1-2-1. Miembros de esta dependencia policial, a bordo de un vehículo, se hicieron presentes en el lugar de los hechos, donde fueron recibidos con disparos de arma de fuego, uno de los cuales causó una herida a la agente Flor de María Meléndez. Los disparos fueron efectuados por el diputado Merino, quien, luego de ser controlado por los agentes policiales, hizo las delicias de los medios de comunicación —especialmente de la prensa escrita-con los disparates que profirió a manos llenas.

El incidente relatado da pie para realizar unas reflexiones que vayan más allá de la simple condena al ex vicepresidente de la república y que ahora se desempeña como diputado por el Partido de Conciliación Nacional (PCN). Lo primero que sale a relucir con el "caso Merino" es la calidad moral de los diputados salvadoreños. Antes de Merino, otros diputados se han visto envueltos en escándalos públicos — pleitos y desórdenes callejeros-, que han puesto de manifiesto sus limitaciones para comportarse con un mínimo de decencia. Aquí es importante dejar claro que no se trata de tener a unos representantes que sean modelo de virtudes morales, pero sí de personas que cumplan unas normas mínimas de decencia pública. Y, por cierto, este mínimo de decencia pública debe ir acompañado de una necesaria honorabilidad por parte de quienes, como los diputados, ejercen cargos de gran responsabilidad en la gestión estatal.

Obviamente, el honor —entendido como aquella cualidad que "lleva al recto cumplimiento del deber y que hace a quien la posee acreedor del respeto de los demás y a la propia estima"2 - es algo ajeno a gran parte de los políticos salvadoreños, incluidos por supuesto varios diputados. Algunos de estos últimos lo han perdido $\longrightarrow$ por lo menos fuertemente socavado- precisamente por sus prácticas abusivas y tramposas ${ }^{3}$. De más está decir que prácticamente ninguno de los que han perdido lanco, Ciro Cruz Zepeda, Francisco Merino, entre los más sonados - han hecho algo para recuperarlo. Al contrario, con una terquedad digna de mejores causas, cuanto más han salido a relucir sus truculencias, más erguidos se han mantenido, soportando estoicamente -o haciendo de cara duras, según se prefiera - los embates de la opinión pública. No hay duda: hay que ser un verdadero pelmazo para soportar, sin siquiera fruncir el entrecejo, las descalificaciones que han caído sobre esos preclaros actores de la política salvadoreña. Más que pelmazo, hay que ser muy cínico o muy poco digno consigo mismo para, tras esas descalificaciones, comportarse como si nada hubiera sucedido, como si los señalamientos de malversación de fondos, tráfico de influencias o incompetencia fueran algo que no tuviera la menor importancia.

Por lo demás, es claro que no tiene sentido condenar el hecho de que los diputados, en el ámbito privado, se emborrachen o comporten como mejor les parezca. Nadie - los medios en particular- debería atribuirse la función de vigilante de la vida privada de los diputados, puesto que ello se podría traducir en una invasión de esferas que son de competencia exclusiva de los individuos. En este punto, se tiene que estar atento a las perversiones a que puede conducir una búsqueda desquiciada de escándalos, que se quieren hacer pasar por noticias de última hora, cuando

2. Manuel Seco, Olimpia Andrés, Gabino Ramos, Diccionario del español actual, Madrid, Aguilar, 1999, p. 2059.

3. Ver "Cuestión de honor", Proceso 860, 23 de junio de 1999, pp. 2-3. 
sólo son chismorreos baratos. La vida privada - la de los diputados al igual que la de cualquier otro ciudadano- es asunto de cada uno. Ahora bien, una cosa es la esfera privada y otra la esfera pública. Y esta última plantea a los diputados -al igual que a todos los que ocupan cargos estatales de importancia - especiales obligaciones: la mínima, no ser protagonistas de escándalos callejeros que perturben la tranquilidad ciudadana. Es claro que pueden hacerlo - Merino es un ejemplo de ello-, pero no deberían; y si lo hacen, tendrían que pagar caro el precio de su irresponsabilidad pública.

No es un buen aliciente para la cultura política democrática que los diputados $\longrightarrow$ políticos de renombre- sean protagonistas de escándalos callejeros y no paguen factura alguna; en esta última situación se estaría dando luz verde para que cualquiera pueda perturbar la tranquilidad de los demás sin ningún cargo de conciencia y con la seguridad de que nadie le va a pedir cuentas por sus actos. Decir que todos lo hacen o que peores cosas suceden en el país es un pésimo argumento, que dice mucho de las pocas luces de quienes lo emiten. Tampoco es una buena defensa afirmar que el comportamiento de Merino fue algo excepcional, cuando la prensa ha informado otros incidentes bochomosos en los que se ha visto implicado el jefe de fracción del Partido de Conciliación Nacional.

Por lo demás, si todos $\longrightarrow$ la mayoría - se emborrachan y disparan a la policía, nada más urgente que aplicar con todo el rigor las leyes para controlar ese tipo de comportamientos; y nada más aleccionador que comenzar a combatir esas prácticas aplicando las merecidas sanciones a un diputado que, al igual que otros salvadoreños irresponsables, gusta de disparar balas por doquier. Asimismo, si bien es cierto que peores cosas suceden en el país - secuestros, asesinatos y violaciones-, eso no quiere decir que deban tolerarse todos aquellos actos criminales que no estén a la altura de los crímenes mayores. Ciertamente, hay crímenes más graves que otros y, según su gravedad, así debe ser la sanción. Pero de eso a suponer que sólo los crímenes mayores cuentan y que los demás deben verse con la mayor naturalidad -o que sus responsables deben ser tratados con especial deferencia - existe un gran trecho, que sólo por ignorancia o complicidad se puede obviar.

En segundo lugar, existe un elemento que añade mayor gravedad al "caso Merino": el diputado portaba un arma de fuego con la cual no sólo amenazó a un vigilante privado, sino que también disparó a la policía. En cualquier otra persona este dato sería menos relevante, pero no lo es en el caso de Merino. Porque si de alguien no puede dudarse que sepa para qué y cómo se usa un arma ese es Francisco Merino. La sospecha fundada acerca de sus vínculos con los escuadrones de la muerte - grupos paramilitares entrenados para asesinar - y su cercanía a Roberto D'Aubuisson - cabecilla de esos grupos, tal como lo revelan documentos desclasificados del gobierno de Estados Unidos-, permite presumir lo que significa un arma de fuego en sus manos. El resultado pudo ser trágico, pues bien pudo haber muerto la mujer policía -u otro compañero suyo- o bien el propio Merino pudo haber resultado herido o, en la peor de las situaciones, muerto. En menudo aprieto estarían los policías que participaron en el incidente de haberse suscitado esta última situación. Es seguro que las autoridades judiciales y la misma Asamblea Legislativa se hubieran empleado a fondo para hundir hasta el cuello a los policías. Porque no hay que engañarse: en El Salvador todavía sigue vigente el esquema que divide a los ciudadanos en dos clases: los de primera y los de segunda. Bajo ese esquema, un policía herido por un diputado no es equivalente a un diputado herido por un policía. Bajo la misma lógica, disparar a la policía no tiene igual significado si quien efectúa los disparos es un diputado, un ciudadano cualquiera o un delincuente. Es absurdo, pero en El Salvador hay quienes pueden ponerse por encima de la ley con una facilidad pasmosa.

Para caer en la cuenta de lo anterior, basta con detenerse en las reacciones de algunos políticos $y$ funcionarios públicos ante los hechos sucedidos en torno al "caso Merino": en casi todas, se minimizó la gravedad de la lesión sufrida por la agente policial. Como contrapartida, sólo unas pocas voces se manifestaron a favor de una pronta investigación, así como de la deducción inmediata de responsabilidades. Ahora bien, ni siquiera al interior de estas voces se escuchó la frase "intento de homicidio", como si disparar un arma en contra de alguien no constituyera un delito de esa naturaleza. Incluso, pareciera que entre los críticos del comportamiento de Merino no se vio como un delito grave disparar contra la policía y herir a uno de sus miembros. ¿Será que pensaron que una persona que dispara un arma contra otra no pone en riesgo su vida? ¿Será 
que creyeron que Merino - forjado en lo mejor del militarismo de la derecha- disparó al parabrisas del vehículo policial sin saber lo que hacía, inocentemente, dominado por los efectos del alcohol? Por los artilugios propios de la tradición jurídica salvadoreña, Merino se ha librado de ver tipificado como "homicidio agravado en grado de tentativa" el acto de haber disparado y herido a una agente policial cuando ésta cumplía sus funciones. La figura de "lesiones graves" le ofrece la oportunidad de ser procesado por una falta leve, cuya sanción no es proporcional al delito cometido ${ }^{4}$.

En tercer lugar, las reacciones ante el "caso Merino" no se han caracterizado sólo por su pretensión de - restarle gravedad al estado de la policía herida, sino también por los absurdos de lo que han hecho gala. Uno de los más socorridos fue la del diputado Gerardo Suvillaga quien, sin ruborizarse, afirmó que "un error cualquiera lo comete", como si el comportamiento de Merino se tratara de una nimiedad de esas a las cuales ni siquiera se les debe prestar atención. De ahora en adelante, contrabandistas, secuestradores, violadores, traficantes y asaltabancos podrán hacerse cargo de la frase proferida por ese padre de la patria: "un error cualquiera lo comete". Como si no bastara con este desatino, el mismo diputado comparó a Merino con Bill Clinton, como si soltar balas contra la policía $-y$ herir a una agente policial- fuera equiparable a tener una aventura amorosa fuera de matrimonio. Por lo demás, si el diputado de marras fuera un poco más lúcido, caería en la cuenta de que las difiçultades que enfrentó Clinton por un amorío serían un juego de niños comparadas con las que tendría que enfrentar si, en estado de ebriedad, hubiera disparado a una policía. Sólo por ingenuidad o ignorancia se puede recurrir al comportamiento de un político norteamericano para justificar los desmanes de un político salvadoreño. Y es que, como señala Vargas Llosa, "Estados Unidos es un país donde el escrutinio a que son sometidos los hombres públicos es el más inmisericorde que existe y de ello derivan excesos, payasadas y también injusticias. Pero derivan algunas cosas muy positivas para el sistema, de esa implacable vigilancia. Allí no hay íconos, hombres providenciales, salvadores de la patria, semidioses... el político en una sociedad así, se vuelve un hombre como los demás, y, en cierta forma, más vulnerable y frágil que el promedio. Eso es sano para la democracia"s.

Entre todas las cosas absurdas que sucedieron en torno al "caso Merino", algo de lo más preocupante fue la reacción del Ministro de Seguridad Pública, Francisco Bertrand Galindo. En efecto, Bertrand Galindo introdujo una expresión que se ha convertido en la preferida en el mundillo de abogados, fiscales y jueces: "el arreglo por conciliación", es decir, el acuerdo privado entre las partes para evadir los procedimientos y las consecuencias de un proceso judicial. Pocos desconocen las trampas propias de este procedimiento: víctimas de atropellos variados aceptan —algunas veces por temor a represalias y otras para no someterse a procedimientos burocráticos interminables- un acuerdo rápido que no repara los daños causados ni satisface los requisitos de justicia que exige el imperio del Estado de derecho. Quizás esté bien como mecanismo subsidiario, pero no como recurso privilegiado para resolver conflictos con implicaciones jurídicas, pues al cederle este lugar, el sistema judicial renuncia a una de sus obligaciones fundamentales, como es la de impartir justicia.

Así, pues, no pudo sino dejar un mal sabor que el Ministro de Seguridad tuviera como primera respuesta a los daños provocados por el diputado Merino el recurso a la "conciliación", alentando aun más la irresponsabilidad prevaleciente en el sistema de justicia. Ese mal sabor se convierte en un franco malestar cuando se sabe que la Fiscalía General de la República, por la tipificación que ha hecho de los delitos cometidos por Merino -lesiones graves, amenazas con agravación especial y daños agravados-, ha dejado la puerta abierta para que la susodicha conciliación se pueda abrir paso y favorezca los intereses del ex vicepresidente de la república. En El Salvador, las cosas no pueden ir peor: los diputados comuptos, incapaces y pendencieros no están solos; junto a ellos están todos aquellos funcionarios que aunque sea responsabilidad suya velar por el cumplimiento de las leyes, hacen justamente lo contrario: socavan los mecanismos legalmente establecidos para combatir la criminalidad y, con ello, fomentan la impunidad.

Por último, el "caso Merino" obliga a prestar la debida atención al tema de la portación de armas de

4. Ver "La constitucionalidad del fucro", Proceso $918,13 \mathrm{dc}$ septicmbre de 2000, pp. 8-9.

5. Mario Vargas Llosa, “El culcbrón del Capilolio”. En Desafios..., pp. 74-75. 
fuego. A veces pareciera que no se cae en la cuenta de una terrible realidad: que las armas están hechas para matar y que en manos de personas irresponsables -que pueden ser diputados borrachos, vecinos enfurecidos o delincuentes- se convierten en una amenaza para la seguridad ciudadana. Por más que se esfuercen los adalides de la armamentización de la sociedad en demostrar lo contrario, su portación legal no es garantía de nada; allí está el diputado Merino para atestiguarlo. Las estadísticas deberían constituir una razón de peso para erradicar de una vez por todas la tenencia y portación de armas de fuego en manos de civiles: en efecto, según un estudio reciente sobre el tema", "durante 1999 murieron cinco personas diariamente a causa de un arma de fuego. En 1995, el porcentaje de muertes a causa de estos artefactos, sobre el total de los homicidios cometidos en el área metropolitana de San Salvador, apenas superaba el 50 por ciento; en 1997, se elevó al 56 por ciento; en 1998, el porcentaje ya era del 60 por ciento. No hay razones para explicar esa tendencia hacia el aumento, más que suponer que la acumulación de armas de fuego en manos de la población y el aprendizaje en el uso de las mismas, está cobrando cada vez más víctimas y está influyendo de manera importante en la violencia que abate al país"”.

Pero no se trata sólo de estadísticas, sino de una dosis mínima de sentido común. Armas de fuego regadas por doquier y en manos de personas con las más diversas características psico-sociales y los más diversos estilos de vida, constituyen una amenaza permanente para la seguridad ciudadana. Creer que unas exiguas exigencias legales van a reducir los riesgos que se derivan de la tenencia y portación de armas de fuego es uno de los peores equívocos. Como se menciona en un editorial del semanario
Proceso, "todos deberíamos estar claros - las instancias de gobierno antes que nadie- de que las armas están hechas para matar y que las personas armadas - sean el padre o los hijos en la casa, el compañero de trabajo o el vecino de la mesa de al lado en el bar- son una amenaza para el entomo inmediato en el que se mueven... Al multiplicarse la tenencia y portación de armas en manos tanto de personas honestas y honorables como de otras que no lo son, pero lo parecen - porque tienen los recursos políticos y económicos para pasar por tales-, la erradicación de ese foco de violencia se vuelve más difícil'”.

Tras esta somera evaluación de la calidad moral de los diputados salvadoreños —en la cual, aunque han salido otros nombres, se ha tomado a Francisco Merino como caso "ejemplar"-, es pertinente retomar el sentido del título de este comentario: “¿Diputados a la medida?”. Pues bien, ¿diputados a la medida de qué o de quién? A la medida de los salvadoreños. Porque, ante los absurdos de la política salvadoreña y ante la apatía (y resignación) de la población ante esos absurdos, es pertinente hacerse la siguiente pregunta: ¿será que los salvadoreños tienen los diputados que se merecen? Obviamente, una respuesta positiva a esta interrogante sería de lo más desesperanzador para todos aquellos que creen que este pueblo se merece un futuro mejor. Una respuesta negativa, sobre todo si es precipitada, podría dar lugar a un optimismo infundado. Con todo, la precariedad de la política salvadoreña invita a preguntarse de nueva cuenta por la veracidad o falsedad de ese viejo lema que dice que cada país tiene los gobernantes que se merece.

\section{Luis Armando González}

6. José Migucl Cruz, María Antonicta Bcltrán, Las armas de fuego en El Salvador. Situación e impacto sobre la violencia, San Salvador, IUDOP, 2000.

7. Ibid., p. 38

8. “¿Continuaremos en la barbaric?”, Proceso 862, 7 de julio de 1999, pp. 2-3. 